\title{
Laparoscopy offers better clinical outcomes and long-term survival in patients with right colon cancer: experience from national cancer center
}

\author{
Muhammad Fahd Shah ${ }^{1}$, Awais Naeem ${ }^{1}$, Ihtisham ul Haq ${ }^{1}$, Shehryar Riaz ${ }^{1}$, Osama Shakeel ${ }^{1}$, \\ Sofoklis Panteleimonitis ${ }^{2}$, Shahid Khattak ${ }^{1}$, Aamir Ali Syed ${ }^{1}$, Amjad Parvaiz ${ }^{1,2,3}$ \\ ${ }^{1}$ Department of Surgical Oncology, Shaukat Khanum Memorial Cancer Hospital and Research Centre, Lahore, Pakistan; ${ }^{2}$ Department of \\ Surgery, School of Health and Care Professions, University of Portsmouth, Portsmouth; ${ }^{3}$ Department of Surgery, Poole Hospital NHS Trust, \\ Poole, United Kingdom
}

Purpose: Laparoscopic approach to colonic tumor requires skill set and resources to be established as routine standard of care in most centers around the world. It presents particular challenge in country like Pakistan due to economic constrain and lack of teaching and training opportunities available for surgeons to be trained to deliver such service. The aim of this study is to look into changing practice of our institution from conventional approach of open to laparoscopic surgery for right colon cancer.

Methods: Consecutive patients between January 2010 to December 2018 who presented to Shaukat Khanum Memorial Cancer Hospital and Research Centre with diagnosis of right colon (cecum, ascending and transverse colon) adenocarcinoma and underwent surgical resections were included in this study.

Results: A total of 230 patients with adenocarcinoma of the right colon underwent curative resections during the study period. Of these, 141 patients (61.3\%) underwent laparoscopic surgery while open resection was performed in 89 patients (38.7\%). Five-year disease-free survival (DFS) of patients with American Joint Committee on Cancer (AJCC) stage III (80.9\% vs. $54.8 \%, \mathrm{P}=0.021$ ) was significantly better if these patients underwent laparoscopic surgery while a trend toward better DFS (96.7\% vs. $84.1 \%, \mathrm{P}=0.111)$ was also observed in AJCC stage II patients, although this difference was not significant. Conclusion: This study demonstrates the adoption of a laparoscopic approach for right colon cancer over 10 years. With a standardized approach and using the principle of oncological surgery, we incorporated this in our minimally invasive surgery practice at our institution.

Keywords: Minimally invasive surgical procedures; Laparoscopy; Right hemicolectomy; Ascending colon

\section{INTRODUCTION}

Colorectal cancer is the third most deadly and 4th most commonly diagnosed cancer in the world [1]. Colonic resection is

Received: Jan 17, 2021 - Revised: Mar 8, 2021 - Accepted: Mar 9, 2021 Correspondence to: Muhammad Fahd Shah, MRCS, FCPS

Shaukat Khanum Memorial Cancer Hospital and Research Centre, 7A Block R-3 M.A. Johar Town, Lahore, Pakistan

Tel: +92-3002382519, Fax: +92-42-359-45209

E-mail:dr_fahdshah@hotmail.com, fahdshah@skm.org.pk

ORCID: https://orcid.org/0000-0001-7316-9569

(C) 2022 The Korean Society of Coloproctology

This is an open-access article distributed under the terms of the Creative Commons Attribution NonCommercial License (https://creativecommons.org/licenses/by-nc/4.0) which permits unrestricted noncommercial use, distribution, and reproduction in any medium, provided the original work is properly cited. considered the only curative option in resectable tumors. Jacob et al. [2] first described laparoscopic surgery for colonic resection in 1991. This was followed by a number of randomized controlled trials (COLOR/COST/CLASSIC) showing better short-term outcomes in terms of analgesia requirement, shorter length of stay (LOS), and equivalent oncological outcomes [3-5]. However, due to the learning curve involved in acquiring new skill, laparoscopic surgery was associated with longer operating times and higher costs [3-6].

In rectal cancer, the concept of total mesorectal excision (TME), introduced by Heald [7], has transformed the oncologic outcomes. The basic principle of TME surgery is dissection within the 'Holy plane' between the embryologic mesorectal and parietal fascia. This en bloc resected specimen contains the draining lym- 
phatics, lymph nodes, and blood vessels through which the tumor may spread, hence minimizing local recurrence rates and improving survival [7-9].

For colonic tumors, Hohenberger et al. [10] in 2009 described the concept of complete mesocolic excision (CME) along with the similar concept as rectal cancer surgery [10]. The concept of CME also encompasses dissection in embryological plane, central vascular ligation to remove all lymph nodes along the vessels, and adequate proximal and distal margins of bowel [10]. Several studies have advocated the efficacy of CME in terms of improved oncological outcomes [11, 12].

Laparoscopic approach to colonic tumor requires skill set and resources to be established as routine standard of care in most centers around the world. It presents particular challenge in a country like Pakistan due to economic constrain and lack of teaching and training opportunities available for surgeons to be trained to deliver such service. Shaukat Khanum Memorial Cancer Hospital and Research Centre (SKMCH\&RC) is a specialized cancer hospital that receives the largest number of colorectal cancer patients in the country.

The aim of this study is to look into changing practice of our institution from conventional approach of open to laparoscopic surgery for right colon cancer. We also analyze the impact this paradigm shift had on short-term clinical outcomes and longterm survival for right colon cancer. The study also looks at the factors responsible for the successful implementation of such program with in depth analysis of the short-term clinical outcomes and long-term survival of patients undergoing laparoscopic surgery for right colon cancer.

\section{METHODS}

Consecutive patients between January 2010 to December 2018 who presented to SKMCH\&RC with diagnosis of right colon (cecum, ascending and transverse colon) adenocarcinoma and underwent surgical resections, were included in this study. Patients undergoing right colon surgeries performed for all other reasons were not included in the study.

All patients with a histologically confirmed right colon adenocarcinoma were discussed in a multidisciplinary team (MDT) meeting on a weekly basis, where decisions were made with consensus regarding the best individual treatment option for the patients. In general, all patients with resectable right colon cancers underwent upfront surgery with adjuvant chemotherapy dependent on histopathology.

Postoperative care was standardized, patients entered into an enhanced recovery program, and were discharged home when assessed as meeting set criteria for discharge. Patients were followed up at 10 days and 6 weeks following their surgery and had subsequent 6-month follow-up appointments for the first 2 years and further annual clinic appointments up to 5 years. The colonoscopy was performed at 1 - and 4 -year following surgery. Com- puted tomography scans of the chest, abdomen, and pelvis were performed on an annual basis for the first 3 years and at 5 th year. The ethical approval was obtained from the Institutional Review Board of SKMCH\&RC (No. Ex-16-03-20-01-A1) with a waiver for informed consent. The study complies with the SKMCH\& RC guidelines on research involving human subjects.

\section{Laparoscopic surgical technique}

All operations were either performed or closely supervised by 2 consultant surgeons. Laparoscopic right hemicolectomy is performed by using 4 working ports including a supraumbilical optic port (Fig. 1). 'Medial to lateral' approach is used as the mesocolon is incised along the mesenteric axis. The ileocolic vessels are clipped and transected close to their origin. After exposing the mesocolic interface, a wide separation between the pancreatic head and the transverse colon is achieved. Dissection then proceeds along the superior mesenteric vein, exposing the gastrocolic trunk of Henle. The middle colic artery is then identified as it rises from the superior mesenteric artery and is transected at the root of its right branch in case of right hemicolectomy or at the origin of middle colic artery in case of extended right hemicolectomy. This is accompanied by lymph node dissection, taking care to preserve the left branch of the middle colic artery. The fascia is detached between the omentum and transverse mesocolon and the hepatic flexure is mobilized. Mobilization of bowel is completed. The specimen is extracted by a minilaparotomy $(5 \mathrm{~cm}$ small midline or right upper quadrant transverse incision), and an extracorporeal, stapled, side-to-side anastomosis is performed.

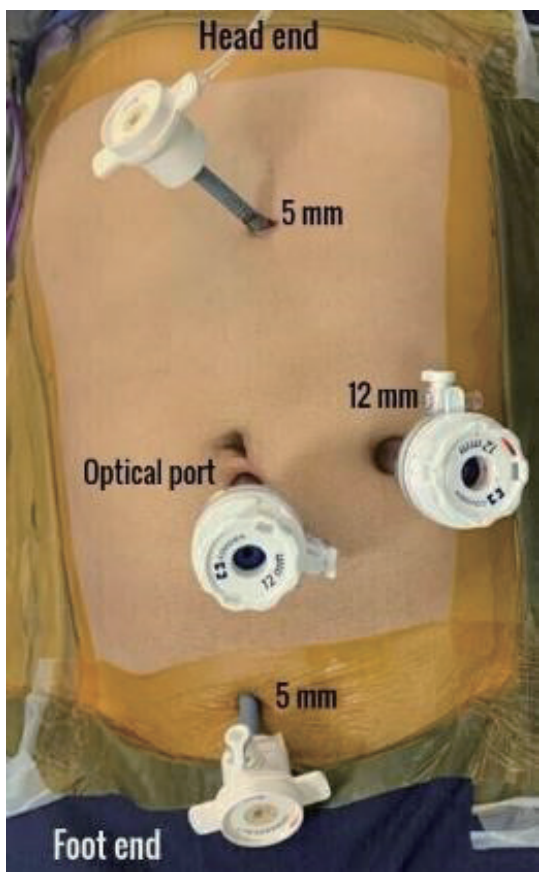

Fig. 1. Laparoscopic port sites. 
Conversion to open surgery is defined, as any incision required facilitating the dissection and mobilization of the specimen or ligation of any vessels. Extraction site is only used to deliver specimen and perform the extra corporeal anastomosis.

\section{Data collection and outcome assessment}

Data was collected in a prospectively maintained database. SK$\mathrm{MCH}$ is a paperless hospital and all patient data is entered in real time into a computerized hospital information system. The hospital has a unique in-house developed a computerized patient management system that collects all patient information in real time including patient demographics, investigations, and MDT discussions, nursing assessments, outpatient, operative notes, and postoperative outcomes. As the data is collected in real time and stored, it allows for accurate retrospective review.

The patients were divided into 2 groups based on whether open or laparoscopic surgery was performed. Baseline variables analyzed were age, sex, body mass index (BMI), preoperative histopathology, treatment received, type of surgery, and American Joint Committee on Cancer (AJCC) stage. Short-term outcomes included operative time, estimated blood loss (EBL), conversion to open, LOS, 90-day mortality, clinical anastomotic leak, lymph node yield, and clear resection margins. Long-term outcomes investigated included local and distant recurrences, 5-year overall survival (OS), and disease-free survival (DFS).

\section{Statistical analysis}

Data analysis was performed using IBM SPSS Statistics ver. 24 (IBM Corp., Armonk, NY, USA). Nonparametric data was expressed as median with interquartile range and parametric data as mean with standard deviation. Cohort demographic and clinical characteristics were compared using the chi-square test or Fisher exact test for categorical variables, Mann-Whitney U-test for nonparametric continuous variables, and t-test for parametric continuous variables. The P-values of $<0.05$ were considered statistically significant.

Kaplan-Meier analysis was used to calculate long-term outcomes. Events included in order to calculate each long-term outcome were; all deaths in case of OS and all deaths and disease recurrences for DFS [13]. Statistical significance was determined by the log-rank test, Breslow test, or Tarone-Ware test as appropriate. Maximum follow-up was set to 5 years and median follow-up time was determined by the Schemper and Smith method [14]. Univariate and multivariate Cox-regression models were applied to identify factors affecting DFS. Outcomes assessed included; age, sex, American Society of Anesthesiologists physical status classification, BMI, presence, and AJCC stage. Data is presented as hazard ratio (HR), 95\% confidence interval, and P-value.

A subgroup analysis of the AJCC stage II and III patients was performed in order to investigate any significant difference in survival in laparoscopic and open surgery for each stage. Cox-regression models were applied as above for this purpose.
Table 1. Baseline characteristics of patients in laparoscopic and open groups

\begin{tabular}{|c|c|c|c|}
\hline Characteristic & $\begin{array}{l}\text { Laparoscopic } \\
\text { group }\end{array}$ & $\begin{array}{l}\text { Open } \\
\text { group }\end{array}$ & P-value \\
\hline No. of patients & 141 & 89 & \\
\hline Age (yr) & $51.2 \pm 13.5$ & $51.3 \pm 13.2$ & 0.945 \\
\hline \multicolumn{4}{|l|}{ Sex } \\
\hline Male & $102(72.3)$ & $56(62.9)$ & 0.134 \\
\hline Female & $39(27.7)$ & $33(37.1)$ & \\
\hline Body mass index $\left(\mathrm{kg} / \mathrm{m}^{2}\right)$ & $24.2(21.4-27.6)$ & $23.5(20.3-27.3)$ & 0.525 \\
\hline \multicolumn{4}{|l|}{ ASA PS classification } \\
\hline I & $11(8.3)$ & $14(18.9)$ & 0.062 \\
\hline$\|$ & $107(80.5)$ & $50(67.6)$ & \\
\hline III & $15(11.3)$ & $9(12.2)$ & \\
\hline IV & $0(0)$ & $1(1.4)$ & \\
\hline $\begin{array}{l}\text { Family history of colorectal cancer } \\
\text { сT }\end{array}$ & $37(26.2)$ & $14(16.1)$ & 0.074 \\
\hline T2 & $2(1.4)$ & $2(2.2)$ & 0.085 \\
\hline T3 & $112(79.4)$ & $59(66.3)$ & \\
\hline T4 & 27 (19.1) & $28(31.5)$ & \\
\hline \multicolumn{4}{|l|}{$\mathrm{cN}$} \\
\hline NO & $32(22.9)$ & $35(40.2)$ & $0.001^{*}$ \\
\hline N1 & $71(50.7)$ & $45(51.7)$ & \\
\hline N2 & $37(26.4)$ & $7(8.0)$ & \\
\hline \multicolumn{4}{|l|}{ pT } \\
\hline $\mathrm{T} 1$ & $1(0.7)$ & $1(1.1)$ & 0.806 \\
\hline T2 & $7(5.0)$ & $7(7.9)$ & \\
\hline T3 & $102(72.3)$ & $61(68.5)$ & \\
\hline T4 & $31(22.0)$ & $20(22.5)$ & \\
\hline \multicolumn{4}{|l|}{ pN } \\
\hline NO & $85(60.3)$ & $49(55.1)$ & 0.656 \\
\hline N1 & 29 (20.6) & 19 (21.3) & \\
\hline N2 & $26(18.4)$ & $21(23.6)$ & \\
\hline N3 & $1(0.7)$ & $0(0)$ & \\
\hline \multicolumn{4}{|l|}{$\mathrm{pM}$} \\
\hline M1 & $2(1.4)$ & $5(5.6)$ & 0.112 \\
\hline Lymphovascular invasion & $8(5.7)$ & $3(3.4)$ & 0.538 \\
\hline Neural invasion & $4(2.8)$ & $5(5.6)$ & 0.309 \\
\hline \multicolumn{4}{|l|}{ AJCC stage } \\
\hline । & $7(5.0)$ & $7(7.9)$ & 0.487 \\
\hline$\|$ & $62(44.0)$ & $33(37.1)$ & \\
\hline III & 71 (50.4) & 47 (52.8) & \\
\hline IV & $1(0.7)$ & 2 (2.2) & \\
\hline
\end{tabular}

Values are presented as number only, mean \pm standard deviation, or number (\%). ASA, American Society of Anesthesiologists; PS, physical status; c, clinical; $p$, pathologic; AJCC, American Joint Committee on Cancer. ${ }^{*} \mathrm{P}<0.05$. 
Table 2. Short-term clinical and pathological outcomes of laparoscopic vs. open patients

\begin{tabular}{lccr}
\hline Variable & $\begin{array}{c}\text { Laparoscopy } \\
\text { group }(\mathrm{n}=141)\end{array}$ & $\begin{array}{c}\text { Open group } \\
(\mathrm{n}=89)\end{array}$ & P-value \\
\hline Operation time (min) & $195(168-241)$ & $170(130-204)$ & $<0.001^{*}$ \\
Estimated blood loss (mL) & $50(30-90)$ & $100(60-120)$ & $<0.001^{*}$ \\
Conversion & $25(17.7)$ & & \\
Length of stay (day) & $5(5.0-6.5)$ & $7(6.0-9.5)$ & $<0.001^{*}$ \\
90-Day mortality & $2(1.4)$ & $11(12.4)$ & $0.001^{*}$ \\
Complication & $14(9.9)$ & $15(16.9)$ & 0.123 \\
Anastomotic leak & $2(1.4)$ & $1(1.1)$ & $>0.999$ \\
Anastomotic leak or pelvic collection & $5(3.5)$ & $7(7.9)$ & 0.151 \\
R0 & $127(97.7)$ & $83(98.8)$ & $>0.999$ \\
Lymph node yield & $18(14-24)$ & $18(15-25)$ & 0.759 \\
\hline
\end{tabular}

Values are presented as median (interquartile range) or number (\%). ${ }^{*} \mathrm{P}<0.05$

Table 3. Five-year long-term outcomes

\begin{tabular}{lcccc}
\hline Variable & $\begin{array}{c}\text { Laparoscopy } \\
\text { group }\end{array}$ & Open group & P-value & $\begin{array}{c}\text { Median } \\
\text { follow-up (mo) }\end{array}$ \\
\hline OS (\%) & 88.9 & 75.7 & $0.033^{\star}$ & 40 \\
DFS (\%) & 88.7 & 66.0 & $0.002^{*}$ & 39 \\
\hline
\end{tabular}

OS, overall survival; DFS, disease-free survival.

${ }^{*} \mathrm{P}<0.05$.

Table 4. Five-year disease-free survival by American Joint Committee on Cancer (AJCC) stage

\begin{tabular}{lcccc}
\hline \multirow{2}{*}{ AJCC stage } & \multicolumn{2}{c}{ Disease-free survival (\%) } & P-value & $\begin{array}{c}\text { Median } \\
\text { follow-up (mo) }\end{array}$ \\
\cline { 2 - 3 } & $\begin{array}{c}\text { Laparoscopy } \\
\text { group }\end{array}$ & Open group & & 36 \\
\hline$\|$ & 96.7 & 84.1 & 0.111 & 36 \\
\hline$\|$ & 80.9 & 54.8 & $0.021^{\star}$ & 34 \\
\hline
\end{tabular}

${ }^{\star} \mathrm{P}<0.05$

\section{RESULTS}

\section{Demographics of the 2 groups}

A total of 230 patients with adenocarcinoma of the right colon underwent curative resections during the study period. Of these, 141 patients (61.3\%) underwent laparoscopic surgery while open resection was performed in 89 patients (38.7\%). The demographic variables, AJCC clinical and pathological stage distribution of both groups are shown in Table 1. Both the groups are comparable without a specific selection process.

\section{Clinical outcomes}

Table 2 summarizes the perioperative, postoperative, and shortterm oncological outcomes of the 2 groups. Operative time (195

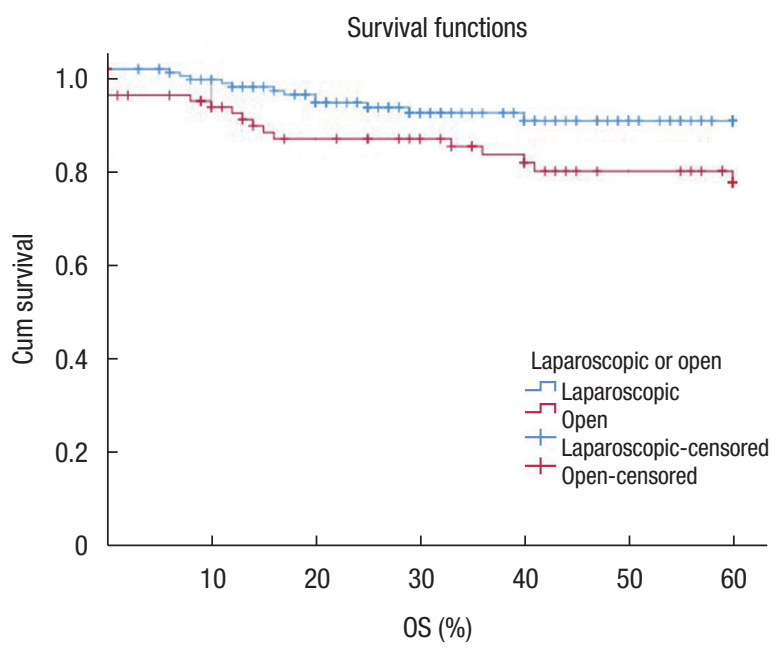

Fig. 2. Five-year overall survival (OS) for laparoscopic vs. open right hemicolectomy.

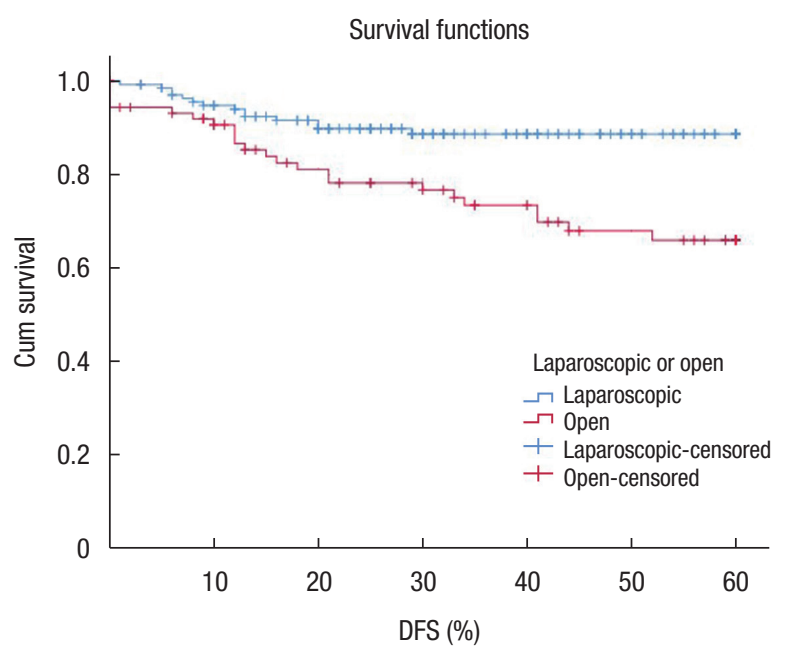

Fig. 3. Five-year disease-free survival (DFS) for laparoscopic vs. open right hemicolectomy.

minutes vs. 170 minutes, $\mathrm{P}<0.001)$ was longer in laparoscopic surgery but EBL ( $50 \mathrm{~mL}$ vs. $100 \mathrm{~mL}, \mathrm{P}<0.001$ ) was lower in patients undergoing minimally invasive surgery (MIS). LOS (5 days vs. 7 days, $\mathrm{P}<0.001)$ and 90 -day mortality $(1.4 \%$ vs. $12.4 \%, \mathrm{P}=0.001)$ were significantly lower in the laparoscopic group. Anastomotic leak rate was comparable in both groups.

\section{Long-term oncological outcomes}

There was a total of 29 deaths (12 laparoscopic, 17 open) and 21 locoregional and distant recurrences (9 laparoscopic, 12 open) in the investigated study cohort. Five-year OS (88.9\% vs. $75.7 \%$, $\mathrm{P}=0.033)$ and 5 -year DFS ( $88.7 \%$ vs. $66 \%, \mathrm{P}=0.002)$ was significantly better in the laparoscopic surgery cohort (Table 3; Figs. 2, 3). Five-year DFS of patients with AJCC stage III ( $80.9 \%$ vs. $54.8 \%$, 


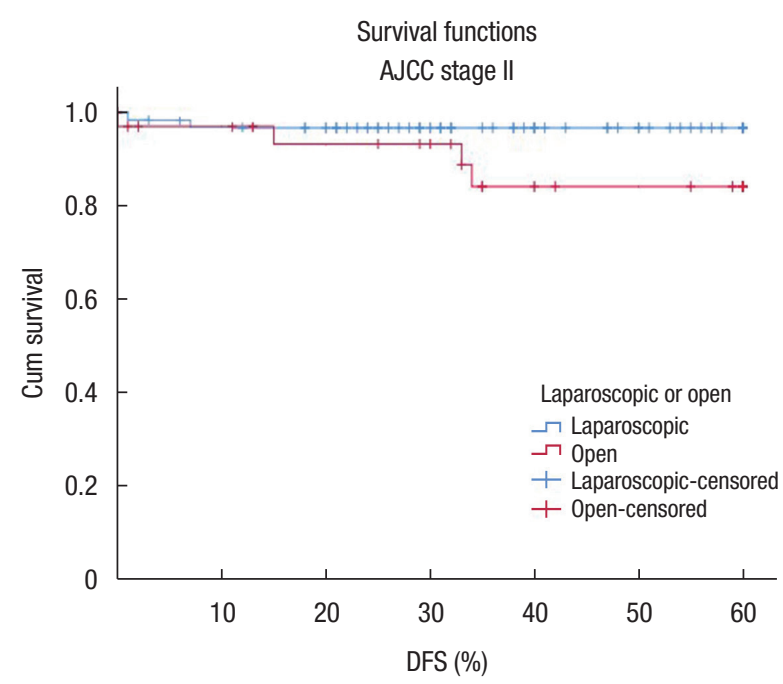

Fig. 4. Five-year disease-free survival (DFS) in American Joint Committee on Cancer (AJCC) stage II patients for laparoscopic vs. open right hemicolectomy.

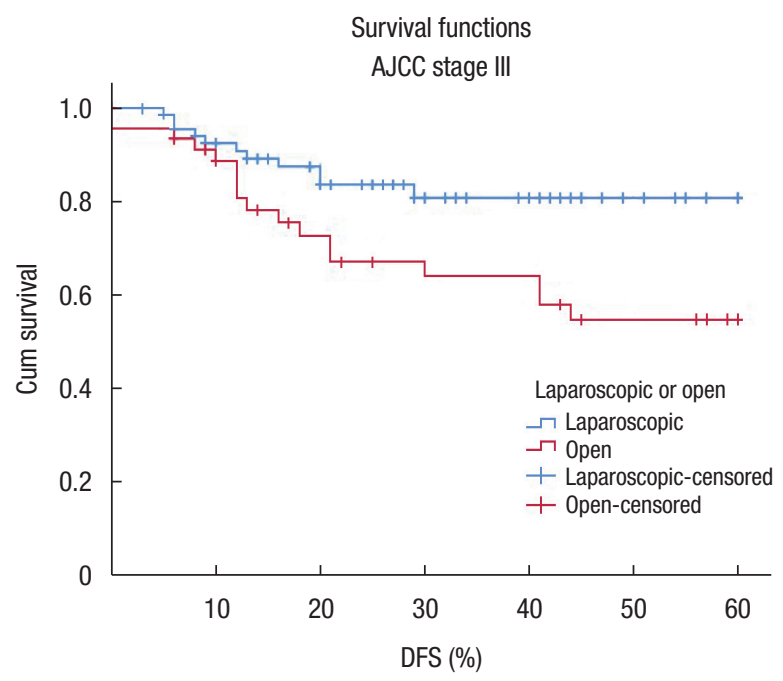

Fig. 5. Five-year disease-free survival (DFS) in American Joint Committee on Cancer (AJCC) stage III patients for laparoscopic vs. open right hemicolectomy.

Table 5. Univariate and multivariate Cox-regression analysis for disease-free survival

\begin{tabular}{|c|c|c|c|c|}
\hline \multirow{2}{*}{ Variable } & \multicolumn{2}{|c|}{ Univariate } & \multicolumn{2}{|c|}{ Multivariate } \\
\hline & $\mathrm{HR}(95 \% \mathrm{Cl})$ & P-value & $\mathrm{HR}(95 \% \mathrm{Cl})$ & P-value \\
\hline Open surgery & $2.762(1.425-5.352)$ & $0.003^{*}$ & 2.881 (1.368-6.067) & $0.005^{\star}$ \\
\hline Male sex & $0.871(0.446-1.703)$ & 0.687 & $0.762(0.358-1.619)$ & 0.479 \\
\hline AJCC stage & 2.945 (1.609-5.392) & $<0.001^{*}$ & 2.064 (1.013-4.203) & $0.046^{\star}$ \\
\hline ASA PS classification & $1.722(0.853-3.476)$ & 0.130 & $2.276(1.062-4.875)$ & $0.034^{*}$ \\
\hline Lymphovascular invasion & $4.931(1.900-12.796)$ & $0.001^{*}$ & $2.372(0.713-7.895)$ & 0.159 \\
\hline Neural invasion & 7.849 (3.386-18.195) & $<0.001^{*}$ & $4.005(1.374-11.672)$ & $0.011^{*}$ \\
\hline Age & $1.008(0.984-1.032)$ & 0.521 & $0.995(0.963-1.028)$ & 0.772 \\
\hline
\end{tabular}

HR, hazard ratio; Cl, confidence interval; AJCC, American Joint Committee on Cancer; ASA, American Society of Anesthesiologists; PS, physical status. ${ }^{*} \mathrm{P}<0.05$.

$\mathrm{P}=0.021)$ was significantly better if these patients underwent laparoscopic surgery while a trend toward better DFS $(96.7 \%$ vs. $84.1 \%, \mathrm{P}=0.111$ ) was also observed in AJCC stage II patients, although this difference was not significant (Table 4; Figs. 4, 5).

Open surgery was associated with worse DFS on univariate (HR, 2.762; $\mathrm{P}=0.003)$ and multivariate $(\mathrm{HR}, 2.881 ; \mathrm{P}=0.005)$ analysis as shown in Table 5.

\section{DISCUSSION}

The goal of curative colon cancer surgery is to remove the tumor with adequate bowel margins along with its accompanying blood supply, lymphatics, and lymph nodes. Numerous randomized controlled trials have shown the benefits of laparoscopy and its oncologic equivalence when compared to open surgery [3-6].

The concept of CME was coined by Hohenberger et al. [10] and encompassed 3 components; dissection in embryologic plane, central venous ligation (CVL), and resection of adequate bowel length. For CME for right-sided colon cancers, mobilization of mesocolon is more radical as compared with 'standard' right hemicolectomy. CVL for right hemicolectomy means exposure of superior mesenteric vessels and anterior surface of pancreas and ligation of ileocolic vessel at the origin. In 'standard' right hemicolectomy, ileocolic vessels are ligated usually $2 \mathrm{~cm}$ from their origin. At our institution, dissection is performed in the embryologic plane and an adequate length of bowel is removed. Ileocolic vessels are ligated at the origin, to the right of superior mesenteric vein. Improved short-term outcomes are reported for laparoscopy in a number of published studies [3]. Recent studies comparing standard laparoscopic vs. open right hemicolectomy have reported a LOS between 6 and 13 days $[15,16]$. In our study, the median hospital stay was significantly lower after laparoscopic 
surgery as compared with open surgery (5 days vs. 7 days, $\mathrm{P}<$ 0.001). Recent studies have shown that the average duration of standard laparoscopic right hemicolectomy was 107 to $207 \mathrm{~min}$ utes $[15,17]$. Mean operative time in our study was higher in laparoscopic procedures (195 minutes vs. 170 minutes, $\mathrm{P}<0.001$ ) that is comparable with that of other studies.

Our conversion rate to open surgery from laparoscopy $(17.7 \%)$ may seem slightly higher than the published series, although with increasing experience with laparoscopy, technically more challenging cases were operated with this technique and this figure seems reasonable in the context of published evidence [18].

Adequate nodal staging is vital in the management of colorectal cancer. Hohenberger et al's study [10] demonstrated better survival in patients having no nodal disease when more than 28 lymph nodes were removed. They also showed the oncologic advantages of CME. With proper CME, the recurrence rate dropped to $3.6 \%$, and 5-year cancer-related survival improved to $89.1 \%$. An Australian study conducted by Bokey et al. [19] also demonstrated improved 5-year OS from 48\% to 63\% and disease-specific survival from $66 \%$ to $76 \%$ after the introduction of CME/CVL. Our study demonstrated an average of 18 lymph node yields which is comparable to published data [18].

Our study has shown better long-term survival for the laparoscopic group with figures of OS of $89 \%$ and DFS of $88.7 \%$ when compared to the open group. Although it is hard to explain this finding, certainly an element of case selection may be responsible for this. As open surgery was reserved for more advanced and larger size tumor, this may have led to slightly worse survival figures. Another important finding of this study is improved survival for AJCC III patients in the laparoscopic group. The possible explanation could be that due to MIS approach, less immune response is seen in these patients, also less blood loss and certainly quicker patient recovery of these patients enabling them to get to adjuvant chemotherapy if required, may have certainly contributed to this fact. Similar survival benefits have been shown in previously published studies too [20].

This study also suffers from its limitations of being retrospective in nature and having a relatively small sample size. But it also presents the consecutive cases and practices from the largest cancer institute in the country with very robust cancer follow-up. Although various published studies have shown better short-term outcomes for laparoscopy in the developed world, we believe that limited resources both in terms of infrastructure and skill gap can be overcome by adopting the principle of oncological surgery and standardization of operative technique. This in return can lead to comparable clinical outcomes and long-term survival for the wider world population.

This study demonstrates the adoption of a laparoscopic approach for right colon cancer over 10 years. With a standardized approach and using the principle of oncological surgery, we incorporated this in our MIS practice at our institution. This study has not only been able to demonstrate the better short-term out- comes often associated with MIS surgery but has shown the survival benefits for the patients with stage III disease undergoing this surgery with MIS approach. However further studies with larger sample sizes and better randomization might provide more evidence on the question of survival benefits.

\section{CONFLICT OF INTEREST}

No potential conflict of interest relevant to this article was reported.

\section{FUNDING}

None.

\section{REFERENCES}

1. Bray F, Ferlay J, Soerjomataram I, Siegel RL, Torre LA, Jemal A. Global cancer statistics 2018: GLOBOCAN estimates of incidence and mortality worldwide for 36 cancers in 185 countries. CA Cancer J Clin 2018;68:394-424.

2. Jacobs M, Verdeja JC, Goldstein HS. Minimally invasive colon resection (laparoscopic colectomy). Surg Laparosc Endosc 1991;1: 144-50.

3. Colon Cancer Laparoscopic or Open Resection Study Group; Buunen M, Veldkamp R, Hop WC, Kuhry E, Jeekel J, et al. Survival after laparoscopic surgery versus open surgery for colon cancer: long-term outcome of a randomised clinical trial. Lancet Oncol 2009;10:44-52.

4. Clinical Outcomes of Surgical Therapy Study Group; Nelson H, Sargent DJ, Wieand HS, Fleshman J, Anvari M, et al. A comparison of laparoscopically assisted and open colectomy for colon cancer. N Engl J Med 2004;350:2050-9.

5. Guillou PJ, Quirke P, Thorpe H, Walker J, Jayne DG, Smith AM, et al. Short-term endpoints of conventional versus laparoscopicassisted surgery in patients with colorectal cancer (MRC CLASICC trial): multicentre, randomised controlled trial. Lancet 2005; 365:1718-26.

6. Jayne DG, Thorpe HC, Copeland J, Quirke P, Brown JM, Guillou PJ. Five-year follow-up of the Medical Research Council CLASICC trial of laparoscopically assisted versus open surgery for colorectal cancer. Br J Surg 2010;97:1638-45.

7. Heald RJ, Husband EM, Ryall RD. The mesorectum in rectal cancer surgery: the clue to pelvic recurrence? Br J Surg 1982;69:6136.

8. Heald RJ, Ryall RD. Recurrence and survival after total mesorectal excision for rectal cancer. Lancet 1986;1:1479-82.

9. Silen W. Mesorectal excision for rectal cancer. Lancet 1993;341: 1279-80.

10. Hohenberger W, Weber K, Matzel K, Papadopoulos T, Merkel S. Standardized surgery for colonic cancer: complete mesocolic excision and central ligation--technical notes and outcome. 
Colorectal Dis 2009;11:354-64.

11. West NP, Hohenberger W, Weber K, Perrakis A, Finan PJ, Quirke P. Complete mesocolic excision with central vascular ligation produces an oncologically superior specimen compared with standard surgery for carcinoma of the colon. J Clin Oncol 2010; 28:272-8.

12. Adamina M, Manwaring ML, Park KJ, Delaney CP. Laparoscopic complete mesocolic excision for right colon cancer. Surg Endosc 2012;26:2976-80.

13. Hudis CA, Barlow WE, Costantino JP, Gray RJ, Pritchard KI, Chapman JA, et al. Proposal for standardized definitions for efficacy end points in adjuvant breast cancer trials: the STEEP system. J Clin Oncol 2007;25:2127-32.

14. Schemper M, Smith TL. A note on quantifying follow-up in studies of failure time. Control Clin Trials 1996;17:343-6.

15. Baker RP, Titu LV, Hartley JE, Lee PW, Monson JR. A case-control study of laparoscopic right hemicolectomy vs. open right hemicolectomy. Dis Colon Rectum 2004;47:1675-9.
16. Ng SS, Lee JF, Yiu RY, Li JC, Leung WW, Leung KL. Emergency laparoscopic-assisted versus open right hemicolectomy for obstructing right-sided colonic carcinoma: a comparative study of short-term clinical outcomes. World J Surg 2008;32:454-8.

17. Zheng MH, Feng B, Lu AG, Li JW, Wang ML, Mao ZH, et al. Laparoscopic versus open right hemicolectomy with curative intent for colon carcinoma. World J Gastroenterol 2005;11:323-6.

18. Bonjer HJ, Hop WC, Nelson H, Sargent DJ, Lacy AM, Castells A, et al. Laparoscopically assisted vs open colectomy for colon cancer: a meta-analysis. Arch Surg 2007;142:298-303.

19. Bokey EL, Chapuis PH, Dent OF, Mander BJ, Bissett IP, Newland RC. Surgical technique and survival in patients having a curative resection for colon cancer. Dis Colon Rectum 2003;46:860-6.

20. Lacy AM, Delgado S, Castells A, Prins HA, Arroyo V, Ibarzabal A, et al. The long-term results of a randomized clinical trial of laparoscopy-assisted versus open surgery for colon cancer. Ann Surg 2008;248:1-7. 